\title{
Impact of BRCA1 mutation on survival after early onset breast cancer
}

\author{
T Huzarski ${ }^{1}$, T Byrski ${ }^{1}$, J Gronwald ${ }^{1}$, B Górski ${ }^{1}$, W Domagała², C Cybulski ${ }^{1}$, Ping Sun ${ }^{15}$, O Oszurek ${ }^{1}$, M Szwiec ${ }^{3}$, \\ K Gugała ${ }^{4}$, M Stawicka ${ }^{5}$, Z Morawiec ${ }^{6}$, T Mierzwa $^{7}$, H Janiszewska ${ }^{8}$, E Kilar ${ }^{9}$, E Marczyk ${ }^{10}$, B Kozak-Klonowska ${ }^{11}$, \\ M Siołek ${ }^{11}$, D Surdyka ${ }^{12}$, R Wiśniowski ${ }^{13}$, M Posmyk $^{14}$, J Lubiński $^{1}$, SA Narod ${ }^{15^{*}}$, Polish Breast Cancer Consortium ${ }^{1}$
}

From Annual Conference on Hereditary Cancers 2012

Szczecin, Poland. 30-31 August 2012

\section{Purpose}

To estimate and to compare ten-year survival rates in unselected patients with early-onset breast cancer, with and without a BRCA1 mutation. To identify prognostic factors among unselected BRCA1-positive breast cancer patients.

\section{Patients and methods}

3354 women who were diagnosed with stage I to stage IV breast cancer, at or below 50 years of age, between January 1996 and December 2006 were contributed from 17 clinical centers in Poland. All patients were offered genetic testing for three founder mutations in BRCA1 (5382insC, C61G, 4184delA). Information on tumour characteristics at presentation and on treatments received was retrieved by reviewing the medical records. Mortality and dates of death were obtained by linkage to the vital statistics database of the Polish Ministry of Administration and Internal Affairs. Survival curves for the mutation-positive and mutation-negative sub-cohorts were constructed using Kaplan-Meier statistics and compared. Predictors of survival were determined using the Cox proportional hazards method.

\section{Results}

3354 patients were enrolled in the study, of whom 234 (7.0\%) were found to carry a BRCA1 founder mutation. The average age of diagnosis was 44 years (range 21 to 50 years). The ten-year survival for mutation carriers was $80.9 \%$ (95\% CI $75.4 \%$ to $86.4 \%$ ) and for non-carriers was $82.1 \%$ (95\% CI $80.5 \%$ to $83.7 \%$ ). After adjusting for other prognostic variables, the hazard ratio associated with

\footnotetext{
${ }^{15}$ Women's College Research Institute, Toronto, Ontario, Canada Full list of author information is available at the end of the article
}

carrying a BRCA1 mutation was 1.40 (95\% CI: 0.99 to 1.99). Among BRCA1 mutation carriers, in the multivariable analysis, positive lymph node status was a strong predictor of mortality ( $\mathrm{HR}=4.6$; $95 \% 2.1$ to 10.0$)$. Among BRCA1 carriers with a small $(<2 \mathrm{~cm})$ node-negative breast cancer, the ten-year survival rate was $91.7 \%$ and tumour size was not predictive of survival $(H R=1.01$ for $1-2 \mathrm{~cm}$ versus $0-1 \mathrm{~cm}$ tumors). Chemotherapy was associated with improved survival in BRCA1 carriers (adjusted $\mathrm{HR}=0.31$; $95 \%$ CI $0.10-1.00)$ but not in non-carriers $(\mathrm{HR}=1.69$; $95 \%$ CI 0.95 to 2.99). The interaction between chemotherapy, mutation status and survival was statistically significant $(\mathrm{p}=0.009)$.

\section{Conclusions}

The survival of women with breast cancer and a BRCA1 mutation is similar to that of patients without a BRCA1 mutation. For women with a small, node-negative breast cancer and a BRCA1 mutation, the ten-year survival rate was $91.7 \%$. Among women with a BRCA1 mutation, survival was better for women who received chemotherapy than for women who did not receive chemotherapy. Future studies should investigate what is the optimum chemotherapy regimen.

\footnotetext{
Acknowledgements

We would like to thank M Siolek, M Szwiec, H Symonowicz, D Surdyka, O Ashuryk, B Gorski, C Cybulski, T Debniak, R Wisniowski and D Sawka for helping to recruit patients to this study.

\section{Author details}

${ }^{1}$ Department of Genetics and Pathology, International Hereditary Cancer Center, Pomeranian Medical University, ul. Połabska 4, 70-115 Szczecin, Poland. ${ }^{2}$ Department of Pathology, Pomeranian Medical University, ul. Unii Lubelskiej 1, 71-252 Szczecin, Poland. ${ }^{3}$ Regional Oncology Center, ul. Katowicka 66a, 45-061 Opole, Poland. ${ }^{4}$ Department of Pathology, Disctict Specialist Hospital, Olsztyn, Poland. ${ }^{5}$ Regional Oncology Center, Poznań,
} 
Poland. ${ }^{6}$ Department of Oncological Surgery, Regional Oncology Center, Łódź, Poland. ${ }^{7}$ Regional Oncology Hospital, Bydgoszcz, Poland. ${ }^{8}$ Department of Clinical Genetics, Collegium Medicum, Nicolaus Copernicus University, Bydgoszcz, Poland. ${ }^{9}$ Department of Oncology, Disctict Specialist Hospital, Świdnica. ${ }^{10}$ Department of Oncological Surgery, Regional Oncology Center Kraków, Poland. ${ }^{11}$ Regional Oncology Center, Kielce, Poland. ${ }^{12}$ Department of Gynecology, Medical Academy, Lublin, Poland. ${ }^{13}$ Regional Oncology Hospital, Bielsko Biała, Poland. ${ }^{14}$ Regional Oncology Center, Białystok, Poland.

${ }^{15}$ Women's College Research Institute, Toronto, Ontario, Canada.

Published: 10 December 2012

doi:10.1186/1897-4287-10-S4-A19

Cite this article as: Huzarski et al:. Impact of BRCA1 mutation on survival after early onset breast cancer. Hereditary Cancer in Clinical Practice 2012 10(Suppl 4):A19.

\section{Submit your next manuscript to BioMed Central} and take full advantage of:

- Convenient online submission

- Thorough peer review

- No space constraints or color figure charges

- Immediate publication on acceptance

- Inclusion in PubMed, CAS, Scopus and Google Scholar

- Research which is freely available for redistribution

Submit your manuscript at www.biomedcentral.com/submit 